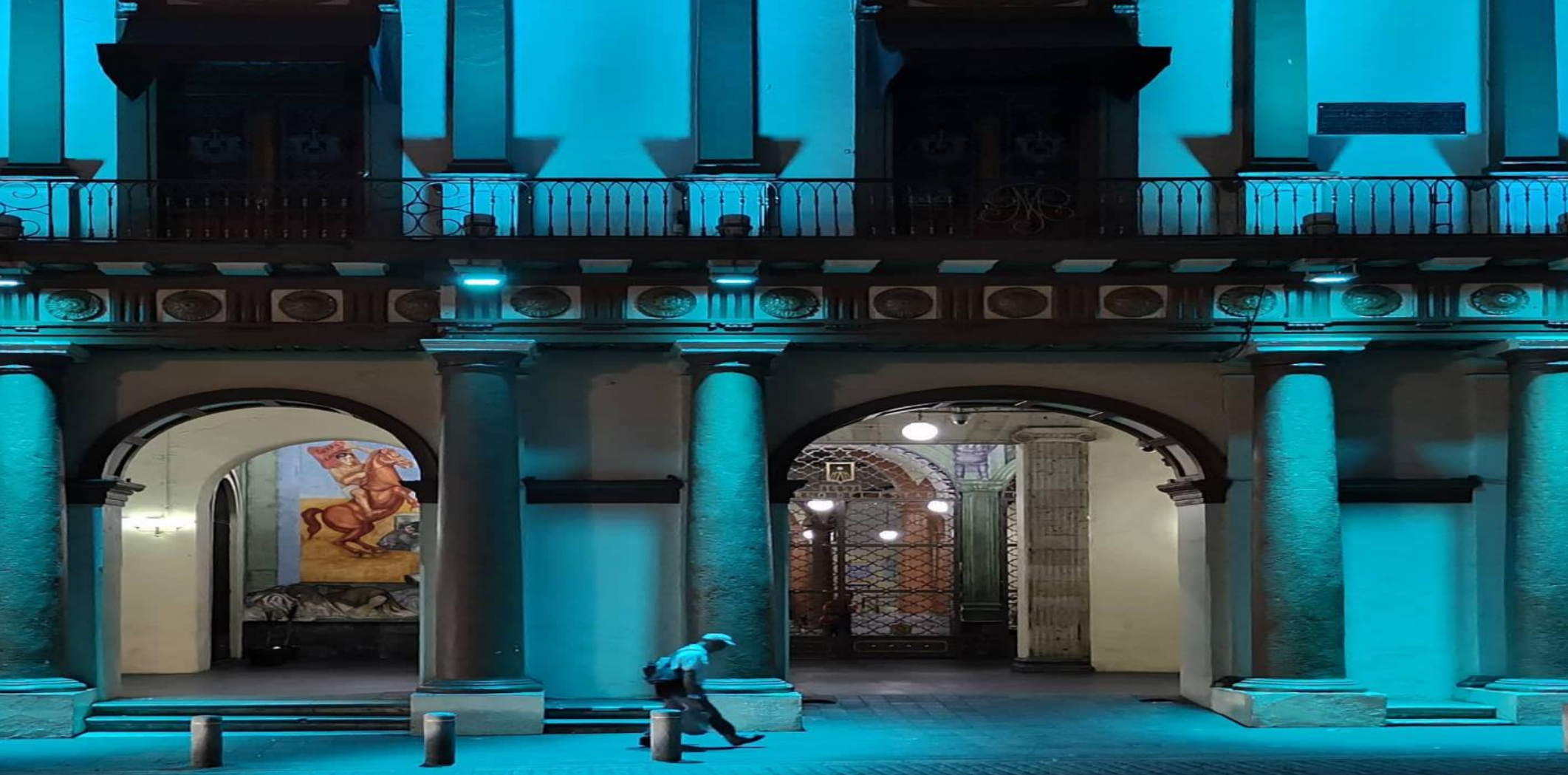

\title{
Centro Histórico de Xalapa desde el imaginario social: historia contada por nosotros mismos
}

Karla Lorena Lozano Merino - Polimnia Zacarías Capistrán ${ }^{b}$

RESUMEN: El artículo se centra en las transformaciones que vive el Centro Histórico de la Ciudad de Xalapa, Veracruz, México; no solo en su forma física, su imagen y formas de vida sino en las que ocurren en las miradas de sus habitantes, en las formas en que construyen referentes de la memoria para descubrir el poder evocativo de los cines provenientes de la primera mitad del siglo xx; edificios hoy desaparecidos o transformados y en abandono, reservorio de vivencias colectivas, de encuentros e interrelación social. A través de los relatos de algunos habitantes, el edificio del antiguo Cine Radio (1939) emerge como un dispositivo, un punto de conexión en el tiempo donde convergen pasado, presente y futuro. ¿Es posible conferir un nuevo sentido de pertenencia a una centralidad histórica fortaleciendo su

\footnotetext{
a Arquitecta, responsable operativa del Observatorio Urbano Universitario de la Facultad de ArquitecturaXalapa, Universidad Veracruzana. Contacto: $\mathrm{k}$ lozanoz2@hotmail.com

${ }^{\mathrm{b}}$ Arquitecta; Maestra en Restauración de Bienes Culturales y Doctora en Arquitectura. Miembro del Sistema Nacional de Investigadores, coordinadora del UVCA-205 Entornos Sustentables, integrante del Observatorio Urbano Universitario y profesora de tiempo completo en la Facultad de Arquitectura-Xalapa, Universidad Veracruzana. Contacto: zpolimnia@yahoo.com.mx

Recepción: 06/enero/2020 
cualidad evocativa, histórica y cultural? ¿Hasta dónde sus habitantes pueden reconstituir significados y ser partícipes de una metamorfosis urbana?

Palabras clave: Centro histórico; imaginario social; cine; narrativa; Historia.

\begin{abstract}
The article focuses on the transformations experienced by the Historic Center of the City of Xalapa, Veracruz not only in its physical form, its image and life forms but in those that occur in the eyes of its inhabitants, in the ways in which they build referents of memory to discover the evocative power of cinemas from the first half of the 20th century; buildings now disappeared or transformed and abandoned, a reservoir of collective experiences, meetings and social interrelation. Through the stories of some inhabitants, the building of the old Cinema Radio (1939) emerges as a device, a point of connection in time where past, present and future converge. Is it possible to confer a new sense of belonging to a historical centrality by strengthening its evocative, historical and cultural quality? How far can its inhabitants reconstitute meanings and participate in an urban metamorphosis?
\end{abstract}

Keywords: Historical Center; Social Imaginary; Movie Theatre; Narrative; History.

\title{
Introducción
}

I

a ciudad de Xalapa desde su propia narrativa: Ciudad de las flores ${ }^{1}$, Atenas Veracruzana², Capital de la cultura ${ }^{3}$, entre otras; se ha transformado a lo largo de los últimos años de manera desfavorable en sus características tanto físicas como en la percepción y uso de sus espacios públicos. Estos cambios se manifiestan en el uso del suelo, la pérdida de sus antiguas funciones, el surgimiento de un buen número de bares y el deterioro o pérdida de varios inmuebles históricos, a esto se suma la imposición de nuevas edificaciones que pasan por encima de las normativas de protección, modificando la imagen urbana de forma drástica, así como las formas de vida de sus residentes. En estos cambios confluyen múltiples factores: desde el impacto de procesos económicos globales de carácter extractivo que han afectado al territorio en su complejidad material, simbólica e histórica; el surgimiento de nuevas centralidades y nuevas identidades, la pobreza urbana, hasta la

\footnotetext{
${ }^{1}$ Nombrada así por el Barón de Humbolt en 1804 debido a su gran variedad de especies florales.

${ }^{2}$ Analogía que alude a la Atenas griega por la concentración del conocimiento, la limpieza de sus calles y la amabilidad de sus habitantes.

${ }^{3}$ Llamada así a nivel nacional al concentrar los eventos culturales más importantes del estado de Veracruz.
} 


\section{Observatorios universitarios - Observatorio Urbano Universitario}

inseguridad y el desinterés de sus municipalidades, incluso de sus propios habitantes. La degradación o pérdida de varios edificios de su centro histórico; importantes y representativos por sus emplazamientos, formas de uso y características arquitectónicas, muestra, al lado de nuevas formas de habitar y de disputar los espacios públicos, que las conformaciones experienciales y narrativas impactan directamente sobre la interacción del espacio público con sus habitantes.

Los residentes de Xalapa desde los inicios de la ciudad e incluso antes de su fundación en 1313 (Bermúdez, 1995) 4 han construido una memoria colectiva de pertenencia y arraigo, de lugares significativos, sucesos y personajes donde las evocaciones y recuerdos anecdóticos forman parte de su historia de vida.

Un claro ejemplo lo podemos encontrar en la remembranza imaginaria de los cines-teatros localizados antiguamente en el Centro Histórico de la ciudad, recordados como hermosos colosos e íconos representativos de la vida recreativa de la Xalapa de los años 50. De estos edificios, mudos testigos de la vida social xalapeña, solo uno se mantiene en pie: el Cine Radio, ubicado en la calle Gutiérrez Zamora, el cual, a pesar de representar la única tipología sobreviviente de aquella época, se encuentra en un estado deplorable de deterioro; teniendo como función un estacionamiento público.

El cúmulo de experiencias vividas a través de los cines nos revela así los llamados fantasmas urbanos (Silva, 2013); nos hace presente el pasado y nos lleva a vivir las transformaciones del entorno construido. Es mediante el actuar y percibir la ciudad por parte de cada uno de los individuos que la conforman, como puede crearse una historia de la realidad de otros tiempos; y es mediante el relato que podemos registrar de manera clara las vivencias de nuestros antepasados, amalgamando así, nuestro entorno presente con el pasado y con una esperanza de futuro. Peter Krieger (2006) refiere que los imaginarios que se guardan en la memoria colectiva de la sociedad son una forma de conocer las ciudades y sus sociedades considerándolas desde un plano histórico y de actualidad, más aún como lo advirtió Clifford Geertz desde los años 70, lo simbólico tiene una existencia concreta y ésta, como lo material, se manifiesta en hechos tangibles, desentrañarlos, es una forma de conocimiento.

En tal sentido, la memoria colectiva de Maurice Halbwachs (1968), las representaciones sociales de Serge Moscovici (1961), los imaginarios sociales de Cornelius Castoriadis (1975) y la explicación interpretativa de Clifford Geertz (1973), constituyen, entre otros, los referentes a

\footnotetext{
${ }^{4}$ Xalapa se formó con la unión de cuatro barrios prehispánicos: Techacapan, Tlalmecapan, Xallitic y Tecuanapan. 
partir de los cuales en las ciencias sociales se estudian las formas en que los habitantes se relacionan socialmente con su entorno, construyen subjetividades y configuran las prácticas cotidianas del habitar. Conservar las memorias de los habitantes de Xalapa es una forma de significar la historia de la ciudad como puede observarse en los trabajos de Blázquez Domínguez (1992).

\section{Espacios con aroma a recuerdo y sabor a nostalgia}

Con el propósito de mostrar la importancia y el significado de los cines xalapeños para la memoria colectiva de la ciudad, haremos un breve recorrido desde la llegada del cinematógrafo como una actividad recreativa y novedosa en el país, observando la manera en que tal actividad impactó en la vida socio cultural y política hasta convertirse en un nuevo modelo de idealización arquitectónica.

Desde finales del siglo XIX se habían edificado en el país más de un centenar de edificios teatrales que habían venido a reconfigurar los símbolos urbanos dominados durante la colonia por la posición jerárquica de parroquias y catedrales (Zacarías, 2003). Lo anterior, se daba en un contexto social, en el que México buscaba estar a tono con los muy avanzados niveles culturales del exterior, aun cuando al mismo tiempo, la nación se encontraba inmersa en un ambiente político-social encaminado más bien hacia una confrontación social derivando en el movimiento armado de 1910. A la par de esta inestabilidad, surgían en la Ciudad de México las primeras señales de una arquitectura que diera cobijo a las nuevas vistas, o imágenes en movimiento, novedoso invento recién patentado por los hermanos Lumière en 1895. Estas funciones fueron absorbidas en un principio por los teatros iniciando su conversión en salas cinematográficas, mientras, iban surgiendo los primeros espacios adaptados. Uno de éstos en la ciudad de México fue el sótano de la droguería Plateros y que más tarde se convertiría en el famoso Salón Rojo, primera sala cinematográfica de la ciudad. A decir de Alfaro y Ochoa (2015) para 1912 la ciudad contaba con 31 sitios de exhibición entre locales y carpas.

Nacido en el año de 1916, uno de los primeros ejemplos representativos de este género de edificios, considerado como pionero de los enormes colosos, es el conocido Cine Opera localizado en la Avenida 16 de septiembre en la Ciudad de México. Este edificio se constituyó en un importante referente al ser el primero en contar con un programa arquitectónico apropiado, mismo que sería la base de los proyectos bajo los que posteriormente se edificarían las innumerables salas cinematográficas en el país; pero, además, por sus características 


\section{Observatorios universitarios - Observatorio Urbano Universitario}

arquitectónicas sobresalientes acordes a la búsqueda incesante de una arquitectura a la vez moderna y nacionalista que enalteciera una nueva identidad mexicana.

El rostro identitario de esta nueva arquitectura hizo que las salas cinematográficas exhibieran elementos decorativos inspirados en un bagaje cultural mexicanizado proveniente de las arquitecturas prehispánica y colonial, mezclados en muchos casos con otros originarios del Art decó. Un eclecticismo modernista acorde a los nuevos tiempos y a los nuevos materiales de construcción. Así se podía mostrar el verdadero cambio de siglo, pues a la vez que conseguían espacios más amplios, cómodos y democráticos, las proyecciones cinematográficas se afincaban como la más popular de las actividades recreativas a diferencia de los exclusivos y para entonces recién abandonados teatros decimonónicos 5 .

Derivado de esta nueva etapa, Xalapa conoció varias edificaciones adaptadas o erigidas ex profeso para albergar la nueva actividad cinematográfica, la mayoría de ellas situadas en el corazón de la ciudad, es el caso del Salón Victoria (1908), enclavado en el Parque Juárez donde funcionó el primer cinematógrafo de esta capital; el antiguo Teatro Cauz, después convertido en Cine Lerdo, ubicado en la calle de Altamirano; del Cine Xalapa, el más grande y moderno de todos, erigido en la década de los setenta por Manuel García Mignoni, (Hernández, 1986), se erigió en la Avenida Ávila Camacho; el Cine Variedades, ubicado a espaldas del Palacio de Gobierno; el llamado Cine-Teatro Limón, hoy todo convertido en un hotel (cabe señalar que desde sus inicios en el primer nivel funcionaba el cine-teatro y en el segundo un hotel); el Teatro Hidalgo, después convertido en Cine Lerdo (en memoria del anterior, para ese entonces ya desaparecido) y después denominado Teatro J. J. Herrera; y del Cine Radio (1939) ubicado, en calle Zamora (ver imagen 1).

La mayoría de estos inmuebles fueron erigidos en la primera mitad del siglo XX, siendo el último de los nombrados, el único que se encuentra aún con un $60 \%$ de su estructura original aun en pie y de los únicos, al lado de los interiores del Cine-Teatro Limón, que fueron erigido siguiendo los patrones arquitectónicos del lenguaje neocolonial.

Es de esta forma que las transformaciones urbanas y la vida cotidiana, nos revelan la complejidad del territorio, los modos de habitarlo, de percibirlo y de actuar en él. A este propósito Gorbea y Soto (1984) refiere sobre la más popular de las actividades recreativas en Xalapa lo siguiente:

\footnotetext{
${ }^{5}$ Recordemos el caso del Teatro Nacional de Santana, erigido en la calle de Vergara en la Ciudad de México, el cual fue demolido en 1904 para dar continuidad a la hoy denominada calle 5 de mayo.
} 
(...) Las proyecciones cinematográficas tienen un gran atractivo para la gente del barrio de San José, y con toda seguridad para el resto de la ciudad. Es el único espectáculo que está al alcance de todos los bolsillos de los xalapeños; las funciones son diarias, y hay cuatro salas con funciones diferentes, para satisfacer la mayor parte de los gustos. Los cines se encuentran ubicados lejos del barrio, y excepto uno de ellos, que es considerado de primera categoría, por tener una sola localidad, cuyo precio de entrada es de tres y cuatro pesos, según el día de la función, los tres restantes son "más populares"; tienen dos y tres localidades; la función más cara, que es la de los domingos o días festivos, no pasa de cuatro pesos, y eso por las noches, pues los domingos hay función de matiné, y los precios fluctúan entre 80 centavos y un peso cincuenta centavos (Gorbea y Soto, 1984: 39).

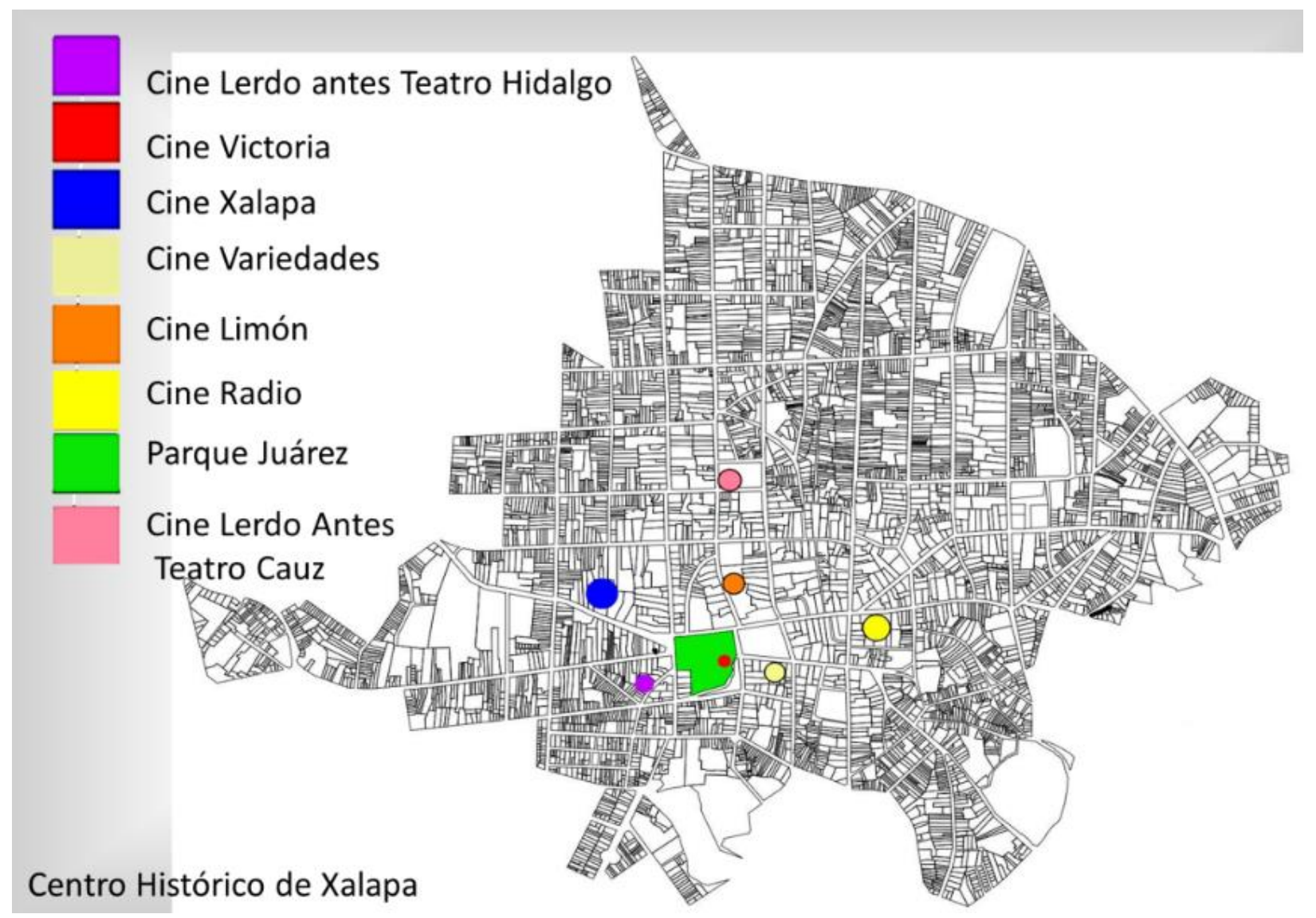

Figura 1. Localización de los antiguos cines en el Centro Histórico de Xalapa Veracruz, México. Fuente documental. Elaboración propia (2019).

\section{Imaginarios y representaciones en el desarrollo de Xalapa}

La ciudad de Xalapa fue testigo del desarrollo progresista durante el período del militar xalapeño Antonio López de Santa Anna, época en la que cobró relevancia al convertirse 


\section{Observatorios universitarios - Observatorio Urbano Universitario}

políticamente en ciudad y gozar del asiento de los poderes estatales de Veracruz. Esta prosperidad, a principios del siglo XX se vio afectada nuevamente por la guerra de Reforma y la Revolución Mexicana, sin embargo el progreso y la experiencia obtenidos en el siglo pasado, no permitieron que la ciudad decayera, por lo que a partir de la conclusión de estos disturbios y con la llegada de gobernadores como: Cándido Aguilar, Heriberto Jara, Adalberto Tejeda, Gonzalo Vázquez Vela y Miguel Alemán tuvo continuidad el desarrollo y mejoramiento de la imagen social y arquitectónica de la ciudad (Blázquez Domínguez, Xalapa, 1980).

Así mismo, otros autores como Pabello Acosta (1991), refieren que en el año de 1950, Xalapa desarrolla una muy importante transformación en su apariencia física, aunque varias calles mantenían su empedrado original y su aire provinciano, la estructura vial se había ampliado, tal es el caso de las avenidas Ávila Camacho, la urbanización de la zona de "Los Lagos" así como la prolongación de la calle Dr. Rafael Lucio, en la cual se comenzaban a desplegar varios comercios, algunos de ellos (la minoría) continúan hasta nuestros días. La ciudad ya contaba con grandes edificios como el Estadio Colón, donde se realizaban concurridos partidos entre la Liga Xalapeña de Béisbol y los equipos de las comunidades aledañas, y el imponente edificio del Estadio Xalapeño que había aportado gran relevancia a la ciudad por su innovador sistema constructivo y cubierta de una sola pieza de concreto.

Es en este contexto de modernidad urbana cuando la cultura empieza a tomar un auge para la sociedad xalapeña y los cines y/o teatros fungen como los sitios de encuentro y de esparcimiento más recurrentes. Sin embargo, muy poca información visual existe de este hecho por lo que recurrimos a la narrativa de la sociedad Xalapeña activa en aquella época, comparándola con la breve información documental localizada y descrita de manera oficial.

Para lograr conocer de cerca la percepción social hacia el Cine Radio se implementó una encuesta a través de las redes sociales dirigida a los habitantes de la ciudad ${ }^{6}$, además se practicaron en torno al inmueble alrededor de 30 entrevistas a personas adultas, esto como parte de un taller comunitario buscando recoger la percepción y remembranzas de los habitantes sobre el espacio. Así mismo, se realizaron visitas a diferentes recintos: parque Juárez, café Parroquia y asilo de ancianos Mariana Sayago (los tres ubicados en el Centro Histórico de la ciudad) con la finalidad de conocer la percepción de los adultos mayores resultando en interesantes narrativas sobre la vida xalapeña de 1950 .Es importante señalar que, durante el proceso se advirtió una revaloración no solo del edificio, sino de la ciudad misma, fungiendo este inmueble como incentivo del recuerdo y de las memorias de la sociedad xalapeña.

\footnotetext{
${ }^{6}$ Encuesta realizada a través de un grupo de Facebook llamado Xalapa Antiguo. 
Los domingos, las familias Xalapeñas salían a disfrutar de la ciudad desde muy temprano con la visita a la Catedral después daban un paseo por los parques, plazas y jardines disfrutando de dulces típicos o acudían a algunos restaurantes importantes de la época, como el conocido “Terraza Jardín” en donde podía tomarse café de Coatepec y por la tarde no podía faltar la visita a algún cine o teatro del Centro Histórico de la Ciudad para disfrutar de alguna película en donde se daba lugar también una combinación entre las clases sociales de la época, todo Xalapa se daba cita, era imposible no encontrar a toda la sociedad xalapeña reunida en estos espacios que además de ser destinados a la cultura, significaban un momento de convivencia y esparcimiento social. En aquellos años gran parte de la vida sociocultural se localizaba precisamente en el Centro de la ciudad. (...) (Narrativa obtenida a través de entrevista a ciudadano Xalapeño, 2016).

Como puede notarse, los ciudadanos gozaban de una gran actividad sociocultural dentro de la cual destacaba la asistencia a los cines o teatros. Razón por la cual, es entendible que estos espacios formen una parte tan importante en la memoria colectiva de la sociedad. Lamentablemente, existen algunos de estos ejemplares que paulatinamente y con el paso del tiempo han ido desapareciendo casi en su totalidad, dejando a su paso solo evocaciones de recuerdos socialmente activos de aquella época (ver tabla 1).

A pesar de estas circunstancias de pérdida, son muy notables los significados que adquieren los espacios de acuerdo con las experiencias vividas por quienes los conocieron, vivencias que podemos conocer gracias a afirmaciones como las siguientes:

Para mí sería una verdadera fortuna volver a revivir mi infancia y algo de juventud.

Era feliz viendo las producciones que llegaban de Hollywood, especialmente las musicales de Gene Kelly, Fred Astaire, Judy Garland, Ann Miller, etc., nunca lo debieron haber degradado a un vulgar estacionamiento (Ciudadano xalapeño, 2016).

“...me recuerda mi juventud, mi novio, que ahora es mi esposo, me llevaba ahí a la matinée, recuerdos tan bonitos, de este cine" (Ciudadana xalapeña, 2016). 
Tabla 1

Relación de cines del siglo XX, su estado y ubicación en Xalapa, Veracruz, México. Elaboración propia (2019)

\begin{tabular}{|c|c|c|c|c|}
\hline CINE & UBICACIÓN & SITUACIÓN & USO ORIGINAL & USO ACTUAL \\
\hline Victoria (1908) & $\begin{array}{c}\text { En los bajos del parque } \\
\text { Juárez }\end{array}$ & Destruido & $\begin{array}{l}\text { Antigua bodega } \\
\text { usada como cine }\end{array}$ & $\begin{array}{l}\text { Anexo del } \\
\text { parque }\end{array}$ \\
\hline $\begin{array}{c}\text { Teatro Cauz } \\
\text { (Después cine Lerdo) } \\
(1920)\end{array}$ & $\begin{array}{l}\text { Calle Manlio Fabio } \\
\text { Altamirano N²5 }\end{array}$ & Demolido & Teatro & Estacionamiento \\
\hline $\begin{array}{l}\text { Cine- Teatro Limón } \\
\text { (1921) }\end{array}$ & Calle Revolución Nº 6 & Cerrado & Teatro Limón & $\begin{array}{c}\text { Hotel en } \\
\text { funcionamiento }\end{array}$ \\
\hline Radio (1939) & $\begin{array}{l}\text { Calle Gutiérrez Zamora } \\
\qquad \text { N }^{\circ} 0\end{array}$ & Deteriorado & Cine & $\begin{array}{c}\text { Estacionamiento } \\
\text { público }\end{array}$ \\
\hline $\begin{array}{c}\text { Teatro Hidalgo, } \\
\text { después Cine Lerdo } \\
\text { (1950) }\end{array}$ & $\begin{array}{l}\text { Calle Miguel Palacios } \\
\qquad \mathrm{N}^{\circ} 12\end{array}$ & Remodelado (2017) & Teatro Hidalgo & $\begin{array}{l}\text { Teatro J.J. } \\
\text { Herrera }\end{array}$ \\
\hline \multicolumn{5}{|c|}{ Cines construidos con otros estilos arquitectónicos } \\
\hline Cinema Pepe (1956) & $\begin{array}{l}\text { Av. Manuel Ávila } \\
\text { Camacho No } 291\end{array}$ & $\begin{array}{l}\text { Reutilizado } \\
\text { (2018) }\end{array}$ & Cine & Cafetería \\
\hline Variedades (1960) & $\begin{array}{l}\text { Calle Ignacio Zaragoza } \\
\text { No } 8\end{array}$ & $\begin{array}{l}\text { Remodelado (1979) } \\
\text { Demolido (2015) }\end{array}$ & Cine & $\begin{array}{l}\text { Edificio } \\
\text { multifuncional }\end{array}$ \\
\hline Xalapa (1970) & $\begin{array}{l}\text { Calle Manuel Ávila } \\
\text { Camacho No } 29\end{array}$ & $\begin{array}{l}\text { Desmantelado y } \\
\text { Reutilizado }\end{array}$ & Cine & $\begin{array}{c}\text { Tienda } \\
\text { departamental }\end{array}$ \\
\hline Sala Tajín (1970) & $\begin{array}{l}\text { Av. Miguel Alemán Nº } \\
109\end{array}$ & Remodelado & Cine & Auditorio \\
\hline $\begin{array}{c}\text { Cinema Carmela Rey } \\
\text { (1980) }\end{array}$ & $\begin{array}{l}\text { Calle Manlio Fabio } \\
\text { Altamirano No } 141\end{array}$ & Remodelado & Cine & Auditorio \\
\hline $\begin{array}{c}\text { Cinema "Los Lagos" } \\
\text { después Kubrik } \\
\text { (1980) }\end{array}$ & $\begin{array}{l}\text { Av. Manuel Ávila } \\
\text { Camacho }\end{array}$ & Reutilizado & Cine & Oficinas \\
\hline $\begin{array}{l}\text { Multicinemas Plaza } \\
\text { Crystal (1980) }\end{array}$ & $\begin{array}{l}\text { Interior de la plaza } \\
\text { comercial Crystal }\end{array}$ & Remodelado & Cine & Cine \\
\hline
\end{tabular}

Elaboración propia (2019).

A mediados de los años 90 comenzaron a surgir en Xalapa otros cines con la entonces novedosa denominación de multicinema, ${ }^{7}$ por lo que, con la llegada de estos nuevos formatos cinematográficos, la significación del edificio para las nuevas generaciones cambió drásticamente resultando en una nueva metamorfosis de la ciudad no solo en esta tipología arquitectónica, sino en todo el Centro Histórico.

\footnotetext{
${ }^{7}$ Estos nuevos cines estaban conformados por más de una sala entre los cuales podemos mencionar: Cinema Pepe, los cinemas Carmela Rey y Claudio Estrada y el Multicinema de Plaza Crystal, entre otros. 
De esta manera los nuevos ciudadanos construyen sus imaginarios frente a nuevas morfologías urbanas y paisajes que distan de aquellas con las que sus antecesores interactuaron. Derivado de esto se utilizó la entrevista para descubrir el nuevo significado del antiguo inmueble en la vida cotidiana de las nuevas generaciones, en dicha actividad participaron personas de entre 15 y 30 años (en la mayoría de los casos ignoraban el uso original del inmueble), como respuesta se obtuvieron las siguientes declaraciones:

"Estaría lindo si quedara como era originalmente, el problema es que acontecen muchos fenómenos paranormales de acuerdo con lo que me platicó un amigo que trabajaba ahí cuando era una mueblería..." (Xalapeño 30 años). “...Es un buen estacionamiento, céntrico y barato, deberían tirar ese edificio para hacer más pisos de estacionamiento” (Xalapeño 25 años). “... No creo que se pueda ver ahí películas, es un edificio viejo y se necesitan cosas nuevas para el centro" (Xalapeño 18 años). "No me gusta, es un edificio que se ve mal, aunque es un estacionamiento barato y bien ubicado ya que tiene dos salidas" (Xalapeño 21 años). "Estaría bien como un espacio cultural pero solo funcionaría si tuviera espacio para estacionarse" (Xalapeño 22 años).

Con base en las expresiones anteriores queda claro que la mayoría de los jóvenes desconocen su significado histórico y hoy solo representa un edificio en ruinas que debería ser demolido. Lo anterior muestra que los valores y significados de los edificios históricos no solo son cambiantes en el tiempo, también difieren en el presente. Así, mientras los jóvenes reclaman cambios y una nueva imagen para el centro histórico, los adultos, defienden lo que constituye un sitio de evocación de un pasado perdido que alimenta su memoria colectiva.

\section{Conclusiones}

Conocer las transformaciones que ha tenido el Centro Histórico de Xalapa, utilizando la narrativa colectiva de su sociedad y la significación de los imaginarios que de ella surgieron demuestra como la sociedad xalapeña ha formado parte activa de la historia de su propia ciudad. La visualización de estos cambios fue posible gracias al análisis de elementos significativos de otra época como en el caso del inmueble Cine Radio (1939), el cual tuvo relevancia por ser el único ejemplar arquitectónico en su tipo y uno de los más antiguos inmuebles en la ciudad de Xalapa. Al utilizarlo como un instrumento evocativo logramos navegar por la memoria colectiva de la ciudad y sus habitantes. Estas tipologías arquitectónicas representativas de la otrora modernidad xalapeña han sido en muchos casos 
degradadas al olvido o incluso subutilizadas con otros fines. Este fenómeno se observa en el Centro Histórico de Xalapa en donde aún queda un número importante de edificios característicos de la arquitectura neocolonial y de la segunda mitad del siglo XX, su protección, hará que no desaparezcan y se mantengan en la memoria colectiva de muchos de sus habitantes.

El extinto Cine Radio, es uno de los muchos ejemplares representativos de este proceso de pérdida, ya que a pesar de ser un testimonio de su época y de la metamorfosis de su entorno físico, social y político, ha caído en el olvido aun siendo reconocido como un importante ícono de la Xalapa de los años cuarenta. El puente temporal que logra configurarse a partir de entender estos inmuebles como instrumentos documentales permite crear un vínculo entre pasado, presente y futuro expresado en la narrativa de una memoria colectiva donde aún se advierten la significación social del edificio y las nuevas expectativas de pertenencia.

Así, la reutilización contemporánea de algunos de estos inmuebles ha contribuido de manera importante a la revitalización del Centro Histórico de Xalapa adquiriendo con ello nuevos significados. Estas nuevas expectativas muestran que las transformaciones en el significado no riñen con la valoración de estos ejemplares, antes bien, los hacen perdurar en el tiempo. Si bien la percepción de los habitantes hacia su ciudad es además de distinta, cambiante, al igual que la precepción sobre los edificios históricos, la vitalidad que se alcanza mediante nuevos usos o la mala imagen urbana causada por su abandono, quedan en la memoria colectiva de los habitantes.

Redirigir la mirada a los antiguos inmuebles para conseguir que adquieran la capacidad de resiliencia ante sus nuevos contextos puede ser la manera más eficiente en la que la sociedad puede ser partícipe de este resultado de cambios a través del tiempo en la ciudad. De esta forma al reutilizar estos espacios, podemos crear conciencia del valor y significado social que representan desde que fueron creados, coadyuvando así mismo a la construcción de una nueva memoria colectiva que cuenta con la capacidad de renovarse con el paso del tiempo permitiendo la preservación del inmueble de forma física y en el imaginario colectivo.

\section{Referencias}

Alfaro Salazar, F. H., \& Ochoa Vega , A. (2015). Espacios distantes...aún vivos las salas cinematográficas de la ciudad de México (Segunda ed.). (P. E. Diseño, Ed.) México, D.F., México : UAM. 


\section{Observatorios universitarios - Observatorio Urbano Universitario}

Bermudez Gorrochotegui, G. (1995). Historia de Jalapa Siglo XVII (Primera ed.). Xalapa, Veracruz , México : Universidad Veracruzana.

Blázquez Domínguez C. (1980). Xalapa, síntesis histórica de los tiempos prehispánicos a la era actual (Primera ed.). Xalapa, Veracruz, México: Gobierno del Estado de Veracruz.

Blázquez Domínguez C. (1992). Xalapa, Veracruz: Imágenes de su história (Primera ed.)(D. Maawad \& A. L. Delgado Edits). Xalapa, Veracruz, México: Archivo General del Estado de Veracruz.

Castoriadis, C. (1975) La institución imaginaria de la Sociedad, Tusquets editores, Buenos Aires. Geertz, C. (1973). The interpretation of cultures. Nueva York: Basic Books Inc.

Gorbea y Soto, A. (1984). Vida y Milagros en San José. Distrito Federal, México, México : Universidad Veracruzana.

Halbwachs, M. (1968). Memoria colectiva y memoria histórica en Reis. Revista española de investigaciones sociológicas, № 69 (1995), pp. 209-219.

Hernandez Palacios , A. (1986). Memorias Jalapa de mis recuerdos. Veracruz: Universidad Veracruzana .

Krieger , P. (2006). Paisajes urbanos: Imagen y memoria. México: UNAM.

Moscovici, S. (1985). Psicología social. Vol.II. Pensamiento y vida social, psicología social y problemas sociales. Barcelona, España. Ediciones Paidós Ibérica, S.A.

Pabello Acosta, R. (1991). Bocetos antiguos de Xalapa. México: Centro Cultural Rubén Pabello Acosta.

Silva, A. (2013). Imaginarios: el asombro social. Bogotá: Universidad Externado de Colombia.

Zacarías Capistrán, P., \& Arellano Jiménez , C. (2003). La Arquitectura de los Teatros Veracruzanos durante el Porfiriato (Primera ed.). Xalapa, Veracruz, México: Universidad Veracruzana. 